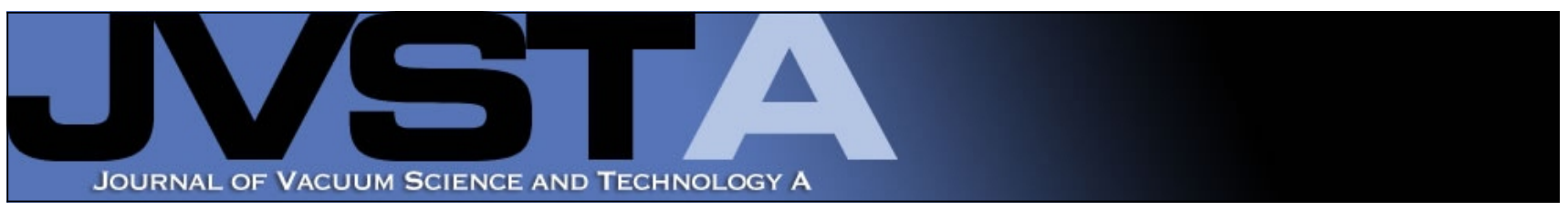

\title{
Synthesis of carbon nitride films at low temperatures
}

P. Hammer, M. A. Baker, C. Lenardi, and W. Gissler

Citation: J. Vac. Sci. Technol. A 15, 107 (1997); doi: 10.1116/1.580481

View online: http://dx.doi.org/10.1116/1.580481

View Table of Contents: http://avspublications.org/resource/1/JVTAD6/v15/i1

Published by the AVS: Science \& Technology of Materials, Interfaces, and Processing

\section{Related Articles}

Low-temperature oriented growth of vanadium dioxide films on CoCrTa metal template on Si and vertical metal-insulator transition

J. Vac. Sci. Technol. A 30, 051502 (2012)

Phase formation and film morphology of ultrathin Co1-xNixSi2 films

J. Vac. Sci. Technol. A 30, 050602 (2012)

Magnetron-sputter epitaxy of $\beta-\mathrm{FeSi} 2(220) / \mathrm{Si}(111)$ and $\beta-\mathrm{FeSi} 2(431) / \mathrm{Si}(001)$ thin films at elevated temperatures J. Vac. Sci. Technol. A 30, 041516 (2012)

Evaporation-assisted high-power impulse magnetron sputtering: The deposition of tungsten oxide as a case study

J. Vac. Sci. Technol. A 30, 040604 (2012)

Comprehensive computer model for magnetron sputtering. I. Gas heating and rarefaction

J. Vac. Sci. Technol. A 30, 041302 (2012)

\section{Additional information on J. Vac. Sci. Technol. A}

Journal Homepage: http://avspublications.org/jvsta

Journal Information: http://avspublications.org/jvsta/about/about_the_journal

Top downloads: http://avspublications.org/jvsta/top_20_most_downloaded

Information for Authors: http://avspublications.org/jvsta/authors/information_for_contributors

\section{ADVERTISEMENT}

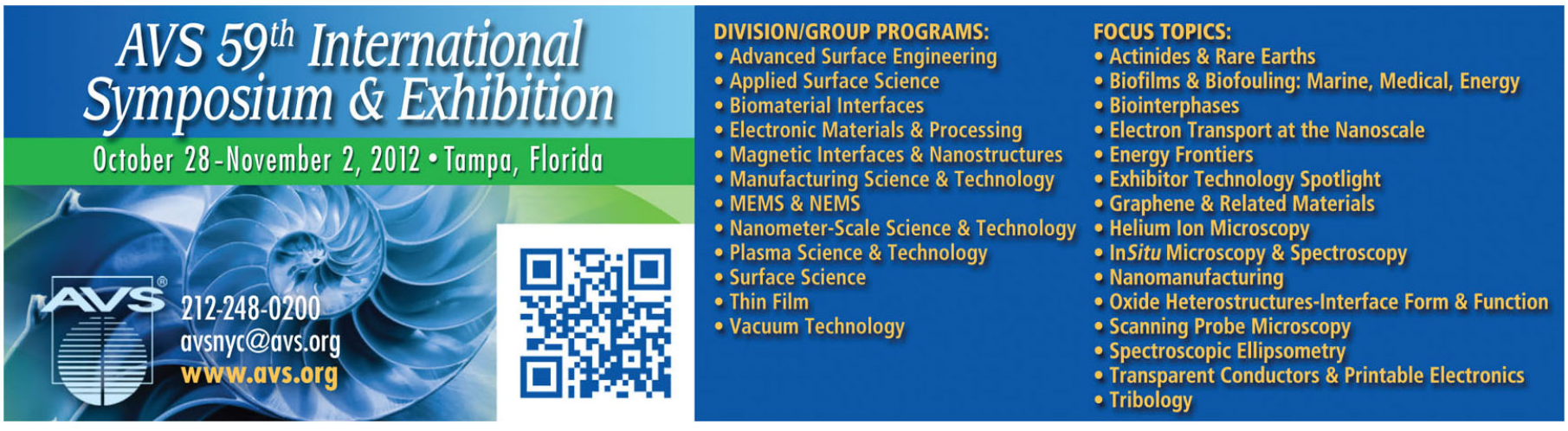




\title{
Synthesis of carbon nitride films at low temperatures
}

\author{
P. Hammer, ${ }^{\text {a) }}$ M. A. Baker, ${ }^{\text {b) }}$ C. Lenardi, and W. Gissler \\ Institute of Advanced Materials, Joint Research Center of the Commission of the European Union, \\ I-21020 Ispra (VA), Italy
}

(Received 7 August 1996; accepted 18 October 1996)

\begin{abstract}
Carbon nitride films $\left(\mathrm{CN}_{x}\right)$ have been deposited by sputtering a graphite target with nitrogen ions. Films were grown both with and without the presence of an assisting focused $\mathrm{N}_{2}$ ion beam. The sputter beam voltage was varied between 150 and $1500 \mathrm{~V}$ and the applied assisting beam voltage from 80 to $500 \mathrm{~V}$. The substrate was held at fixed temperatures between 80 and $673 \mathrm{~K}$. The coatings were characterized with respect to their electrical, optical, and structural properties. The nitrogen content was measured by x-ray photoelectron spectroscopy (XPS) and a maximum nitrogen concentration of 44 at. \% was obtained for a nonassisted sample deposited at $140 \mathrm{~K}$. The chemical structure was investigated by XPS and Fourier transform infrared spectroscopy. Reduction of the substrate temperature in conjunction with low sputter beam voltages $(<200 \mathrm{~V})$ caused the optical band gap to increase up to $2.2 \mathrm{eV}$, the sheet conductivity to decrease to less than $10^{-9}(\Omega \mathrm{cm})^{-1}$ and the density to be reduced to $1.6 \mathrm{~g} / \mathrm{cm}^{3}$. The increasing transparency is accompanied by structural changes indicating a transition from a predominantly $s p^{2}$ bonded amorphous $s p^{2} / s p^{3} \mathrm{C}-\mathrm{N}$ network to a more linear polymerlike structure consisting predominantly of doubly and triply bonded $\mathrm{C}$ and $\mathrm{N}$ atoms. No evidence for the formation of the $\beta-\mathrm{C}_{3} \mathrm{~N}_{4}$ phase was found. (C) 1997 American Vacuum Society. [S0734-2101(97)02801-7]
\end{abstract}

\section{INTRODUCTION}

Recently it has been found that in addition to the well known effect of physical sputtering, chemical sputtering occurs if a carbon film is bombarded with nitrogen ions. ${ }^{1-3}$ Physical sputtering results in the release of neutral carbon atoms from the target. The physical sputter coefficient is a function of energy but can be almost disregarded below 100 $\mathrm{eV}$. Conversely, chemical sputtering leads primarily to the formation of carbon nitride $(\mathrm{CN})$ radicals. These radicals react with themselves to form $\mathrm{C}_{2} \mathrm{~N}_{2}$ or with superficially adsorbed water molecules to form HCN or HOCN. The estimated sputter coefficient has been shown to be about $0.25 \%$ $\pm 20 \%$ [carbon atoms/nitrogen atoms], this value being almost independent of the assisting $\mathrm{N}_{2}^{+}$beam energy in the range of sputter beam voltages of $100-500 \mathrm{~V}$ and about a factor of 3 higher than the physical sputter coefficient for $\mathrm{Ar}^{+}$.

The occurrence of chemical sputtering opens up a new possibility of synthesizing carbon nitride films by dual ion beam sputtering. If contrary to conventional methods, the carbon target is bombarded with nitrogen ions, both neutral $\mathrm{C}$ atoms and nitrogen rich $\mathrm{CN}$ based compounds are sputtered. By variation of the beam energy, it is possible to influence the ratio of these (chemically) sputtered CN compounds and the (physically) sputtered $\mathrm{C}$ atoms. Furthermore, at deposition temperatures below the boiling point of the $\mathrm{N}$ rich compounds, the loss of molecules will be inhibited, increasing the $\mathrm{N}$ content of the film. Finally, if the growing film is bombarded by nitrogen ions, the nitrogen content

\footnotetext{
${ }^{a}$ Present address: Instituto Física Gleb Watagin, Universidade Estadual de Campinas, Departamento di Física Aplicada, UNICAMP, 13083-970 Campinas-SP, Brasil.

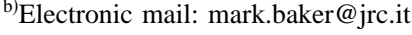

might be further increased and a rearrangement of the deposited atoms and molecules into the desired $\beta-\mathrm{C}_{3} \mathrm{~N}_{4}$ phase ${ }^{4}$ induced by the additional energy transfer.

This article reports on carbon nitride coatings which have been synthesized with this new method. The coatings were characterized by Fourier transform infrared (FTIR), x-ray photoelectron spectroscopy (XPS), x-ray diffraction (XRD), $\mathrm{x}$-ray reflectivity, optical spectroscopy, conductivity, and hardness measurements.

\section{EXPERIMENT}

The dual ion beam sputter deposition apparatus described elsewhere in detail ${ }^{1}$ is equipped with two Kaufman sources of $3 \mathrm{~cm}$ diameter as the sputter and assisting guns. A graphite target (purity $>99.99$ at. \%) was sputtered by nitrogen ions at different voltages between 100 and $1500 \mathrm{~V}$ with a total ion beam current of 18-35 mA. The focused assisting nitrogen ion source was operated at voltages between 80 and $500 \mathrm{~V}$ with a total beam current of $1.5-8.5 \mathrm{~mA}$. Focusing the ion beam graduates the intensity and hence the ion-to-atom arrival ratio at the substrate. At flow rates of $5 \mathrm{sccm}$ for the sputter gun and $2 \mathrm{sccm}$ for the assisting gun, the working gas pressure was maintained at $4 \times 10^{-2} \mathrm{~Pa}$. Sapphire and silicon wafers (100) were used as substrates. These were cleaned in an ultrasonic bath, first with a cleaning solution, then by distilled water and finally in propanol. Before deposition, the vacuum chamber was evacuated by a $450 \mathrm{l} \mathrm{s}^{-1}$ turbomolecular pump to a base pressure of $3 \times 10^{-5} \mathrm{~Pa}$. The substrate holder was cooled down (using liquid nitrogen) or heated up to defined temperatures of $80,140,230,310$, and $673 \mathrm{~K}$, the temperature being monitored by a PT 100 thermocouple. Sputter cleaning of the substrates was performed using a 500 $\mathrm{V} / 10 \mathrm{~mA}$ nitrogen ion beam. 
TABLE I. Details of the deposition parameters and measured properties of $\mathrm{CN}_{x}$ films grown at high and low sputter voltages and substrate temperatures between 80 and $673 \mathrm{~K}$.

\begin{tabular}{ccccccc}
\hline \hline Sample & $\begin{array}{c}\text { Deposition } \\
\text { beam voltage } \\
U_{b}(\mathrm{~V})\end{array}$ & $\begin{array}{c}\text { Substrate } \\
\text { temperature } \\
(\mathrm{K})\end{array}$ & $\begin{array}{c}\text { Optical band gap } \\
E_{\text {tauc }} \\
(\mathrm{eV})\end{array}$ & $\begin{array}{c}\text { Conductivity } \sigma \\
(\Omega \mathrm{cm})^{-1}\end{array}$ & $\begin{array}{c}\text { Hardness } \\
(\mathrm{GPa})\end{array}$ & $\begin{array}{c}\text { Nitrogen } \\
\text { content } \\
(\text { at. \% })\end{array}$ \\
\hline CN42 & 1500 & 673 & 0.20 & 1 & 20 & 24 \\
CN58 & 1000 & 140 & 0.27 & 1 & 8 & \\
CN54 & 150 & 310 & 0.26 & $8.7 \times 10^{-3}$ & 8 & 32 \\
CN65 & 150 & 230 & 0.60 & $1.0 \times 10^{-4}$ & 7 & 44 \\
CN55 & 150 & 140 & 1.35 & $8.0 \times 10^{-10}$ & 1 & 4 \\
CN67 & 150 & 80 & 2.20 & $1.0 \times 10^{-14 a}$ & 1 & \\
\hline \hline
\end{tabular}

${ }^{a}$ Values determined by extrapolation.

Films were analyzed $e x$ situ by XPS with a Riber Nanoscan 50 incorporating a semi-imaging MAC2 analyzer. The spectra were recorded using $\mathrm{Al} K \alpha$ radiation at an energy resolution of $0.5 \mathrm{eV}$. The spectrometer was calibrated on the $\mathrm{Au} 4 f_{7 / 2}$ and $\mathrm{Cu} 2 p_{3 / 2}$ peaks at 83.98 and $932.67 \mathrm{eV}$, respectively. To quantitatively examine $\mathrm{CN}_{x}$ films ex situ by XPS, any surface contamination must be removed with minimal artificially induced changes to the underlying bulk material. The presence of adventitious carbon contamination falsely reduces the nitrogen concentration measured at the surface and distorts the XPS C ls peak shape. ${ }^{5}$ However, sputtering induces a preferential loss of nitrogen. ${ }^{3,5}$ Spectra which most faithfully reproduced the bulk material were obtained after a sputtering to a depth of approximately $6 \AA$. In this trade-off situation, an ion etch to a depth of approximately $6 \AA$ was found to always remove the contamination and induce a maximum loss of 3 at. \% N..$^{5}$ As the $\mathrm{N}$ concentration can only be lowered by these distortive effects, the maximum value obtained before or after the etch was taken, giving an error of up to 2 at. \% in the quoted value. Curve fitting was performed with a nonlinear least-squares fitting program using a mixed Gaussian-Lorenzian product function. A Shirley background was subtracted prior to fitting. Transmission infrared (IR) spectra were measured with a Perkin Elmer FTIR 1600 spectrometer.

$\mathrm{X}$-ray diffraction patterns were measured by an in-house constructed glancing angle $\mathrm{x}$-ray diffractometer. The density was obtained from $x$-ray reflectivity measurements using a Siemens D5000 x-ray diffractometer. For all films, the surface conductivity (Keithly 617 electrometer) and Tauc band gap from UV/vis spectroscopy (Perkin Elmer 551S) have been determined. Hardness measurements were performed by an ultralow load, depth sensing nanoindenter (Nanoindenter II from Nano Instruments Inc.). The measurements were calibrated with a $\mathrm{Si}(111)$ wafer, assuming a modulus of $157 \mathrm{GPa}$, independent of penetration depth. With these assumptions the hardness is $12 \mathrm{GPa}$ for the $\mathrm{Si}$ wafer, also independent of penetration depth.

\section{EXPERIMENTAL RESULTS}

\section{A. Band gap, conductivity, density, and hardness}

Table I lists some of the films synthesized in this work, their deposition parameters, the optical band gap, dark conductivity, hardness, and nitrogen content. As noted previously, ${ }^{2}$ in the presence of an assisting $\mathrm{N}_{2}^{+}$beam, the $\mathrm{N}$ content increases with increasing flux. However, it produced only minor changes in the band gap, dark conductivity, IR absorption, and XPS spectra.

Two $\mathrm{CN}_{x}$ films were deposited at high sputter beam voltages, one deposited at high temperature $(673 \mathrm{~K})$ and the other at low temperature $(140 \mathrm{~K})$. Both films had a dark brown color, an optical (Tauc) band gap of $0.2-0.3 \mathrm{eV}$, and dark conductivity of approximately $1(\Omega \mathrm{cm})^{-1}$. Four films were deposited at low sputter beam voltages of $150 \mathrm{~V}$. Such a decrease in the sputter beam voltage at room temperature is accompanied by a drop in the conductivity to $9 \times 10^{-3}$ $(\Omega \mathrm{cm})^{-1}$. Progressive reduction of the substrate temperature down to $80 \mathrm{~K}$ produces transparent films with a Tauc gap of up to $2.2 \mathrm{eV}$ and a conductivity which further decreases by 12 orders of magnitude. Assisting the growing films under these conditions with an $80-400 \mathrm{~V} \mathrm{~N}_{2}^{+}$beam tended only to slightly reduce the band gap and increase the conductivity.

The effect of decreasing substrate temperature on optical band gap is displayed in Fig. 1. Both values obtained from films sputtered at a high beam voltage (open squares) are low, the reduction of the deposition temperature to $140 \mathrm{~K}$ producing no significant change. Conversely, the film depos-

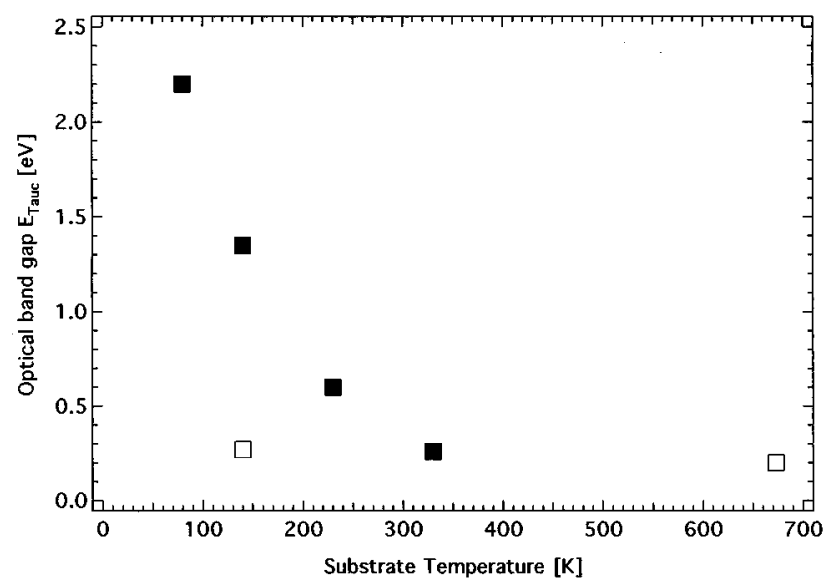

FIG. 1. Optical band gap $\left(E_{\text {tauc }}\right)$ vs deposition temperature for the $\mathrm{CN}_{x}$ films given in Table I (sputter beam voltages: $1000 \mathrm{~V}$ or above-open squares; 150 V-full squares). 
ited at the same temperature, but at a low sputter voltage of $150 \mathrm{~V}$ (full squares) shows a considerably higher band gap of $1.35 \mathrm{eV}$. The highest Tauc gap was found for the film deposited at the lowest substrate temperature of $80 \mathrm{~K}$ and lowest beam voltage.

The hardness of the films depends on substrate temperature, sputter beam voltage, and nitrogen content. For the two films sputtered at high beam voltages (CN42 and CN58), there is a decrease in the hardness from $20(673 \mathrm{~K})$ to $8 \mathrm{GPa}$ $(140 \mathrm{~K})$, whereas for the films sputtered at low beam voltages the hardness is reduced from $8(310 \mathrm{~K})$ to $1 \mathrm{GPa}(80 \mathrm{~K})$. The influence of the beam voltage (assuming similar nitrogen contents) can be seen by comparing the two films sputtered at the same substrate temperature but different beam voltages (CN58 and CN55), the hardness decreasing from 8 to $1 \mathrm{GPa}$, respectively. This decrease in hardness is accompanied by a reduction of the film density from a value of 2.2 for CN58 to $1.6 \mathrm{~g} / \mathrm{cm}^{3}$ for CN67. From substrate bending experiments, it was found that the transparent films are nearly free of internal stress and furthermore, relatively easy to scratch.

Glancing angle x-ray diffraction measurements have shown that both high and low temperature deposited films are $\mathrm{x}$-ray amorphous.

\section{B. IR spectra}

With regard to the changes in chemical structure, Fig. 2 shows the transmission IR spectra for all of the samples in Table I. In addition, the spectrum of $a$-C film sputtered with $\mathrm{Ar}^{+}$at $80 \mathrm{~K}$ is given. In some of the spectra, the peak at approximately $2350 \mathrm{~cm}^{-1}$ is a background contribution due to the presence of traces of $\mathrm{CO}_{2}$ in the measuring chamber.

The $a-\mathrm{C}$ film spectrum is featureless. Incorporation of $\mathrm{N}$ into the structure activates forbidden vibrational modes and absorption bands emerge in the transmission spectrum corresponding to different $\mathrm{CN}$ bonds. Considering first the main band, for high sputter voltages, the structure is similar with the absorption maximum occurring at $1300 \mathrm{~cm}^{-1}$ for CN42 and around $1420 \mathrm{~cm}^{-1}$ for CN58. As the sputter voltage is reduced to $150 \mathrm{~V}$, at $310 \mathrm{~K}$ there is still a broad band with the maximum shifting to about $1520 \mathrm{~cm}^{-1}$, showing that the vibrational frequencies at higher wavenumbers are becoming increasingly active. Interpretation of this very broad band has best been described by Kaufmann et al. ${ }^{6}$ These authors assigned the strong broad band with an absorption maximum at around $1570 \mathrm{~cm}^{-1}$ to be indicative of large $s p^{2}$ domains, corresponding to the Raman " $G$ '" (graphitic) band. At lower wavenumbers, a broad band with the maximum at 1370 $\mathrm{cm}^{-1}$ is considered to represent a more disordered structure with smaller $s p^{2}$ domains and is labeled the " $D$ " (disordered) band. On this basis, the shift in the maximum to higher wavenumbers can be interpreted as representing an increase in the number of aromatic $\mathrm{N}-s p^{2} \mathrm{C}$ bonds. The contribution of the $\mathrm{N}-s p^{3} \mathrm{C}$ bonds, expected at lower wavenumbers, is reduced. As the deposition temperature is reduced to 140 and $80 \mathrm{~K}$, there is much less absorption at lower wavenumbers, more structure, and at $80 \mathrm{~K}$ the maxi-

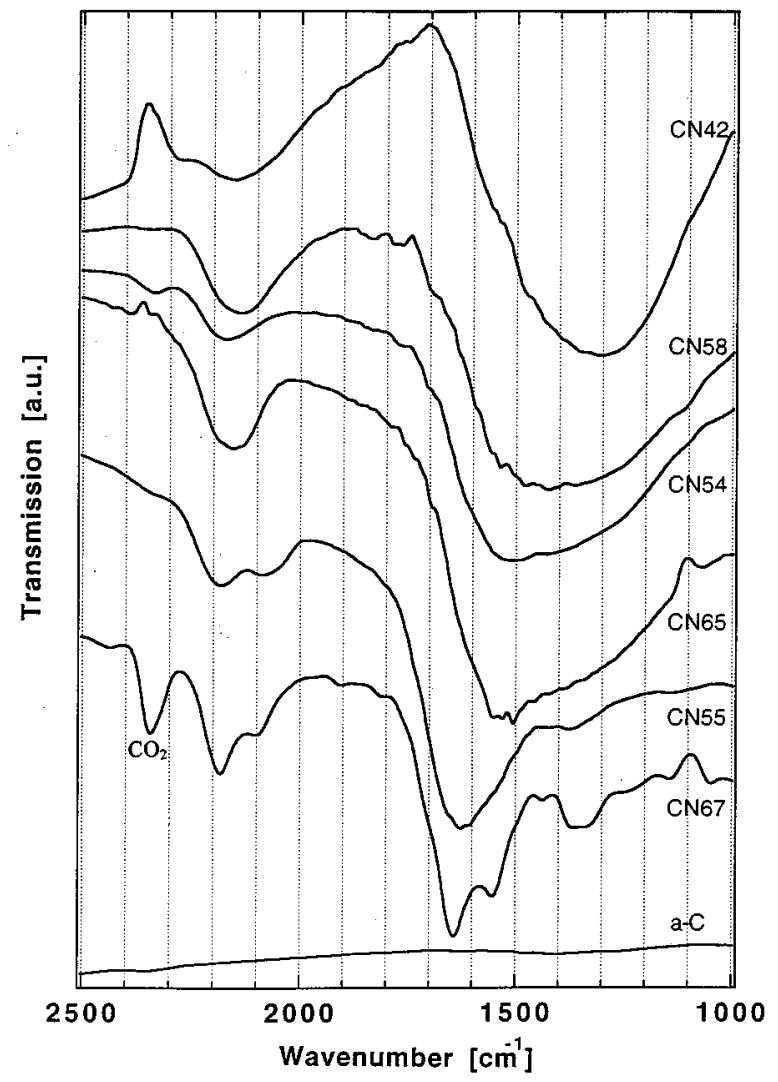

FIG. 2. FTIR transmission spectra of the $\mathrm{CN}_{x}$ films given in Table I CN42 $(1500 \mathrm{~V}, 673 \mathrm{~K})$; CN58 (1000 V, $140 \mathrm{~K})$; CN54 (150 V, $310 \mathrm{~K})$; CN65 (150 $\mathrm{V}, 230 \mathrm{~K})$; CN55 (150 V, $140 \mathrm{~K})$; CN67 (150 V, $80 \mathrm{~K}) ; a$-C film sputtered with $\mathrm{Ar}^{+}$at $80 \mathrm{~K}$.

mum has shifted to about $1645 \mathrm{~cm}^{-1}$. These changes represent, respectively, reduced single bonding, fewer aromatic based structures, and the presence of doubly bonded components. The exact nature of the doubly bonded groups is not determinable due to the overlap of $\mathrm{C}=\mathrm{C}$ and $\mathrm{C}=\mathrm{N}$ stretching vibrations in the $1600-1650 \mathrm{~cm}^{-1}$ region.

For the smaller $2100-2200 \mathrm{~cm}^{-1}$ absorption band, at high deposition voltages, the peak is centered at $2135 \mathrm{~cm}^{-1}$, corresponding to carbodiimide ( $>\mathrm{N}=\mathrm{C}=\mathrm{N}<$ ) and/or isonitrile $(\mathrm{C} \equiv \mathrm{N}-)$ groups. This peak appears for deposited films with $\mathrm{N}$ concentrations above approximately 20 at. \% and (for 673 $\mathrm{K}$ deposited films) increases in intensity with increasing $\mathrm{N}$ content. ${ }^{2}$ For a deposition voltage of $150 \mathrm{~V}$, as the temperature is reduced, the peak narrows, and two components emerge at 2100 and $2190 \mathrm{~cm}^{-1}$. These peak positions correspond to a number of different possible bonding configurations found in the literature. ${ }^{7,8}$ Of particular interest are the absorption frequencies of $\mathrm{HCN}$ and $\mathrm{C}_{2} \mathrm{~N}_{2}$, occurring at 2095 and $2165 \mathrm{~cm}^{-1}$, respectively. Another possible configuration found is that of a chain containing $\mathrm{N}$, doubly bonded $\mathrm{C}$, and terminating in a nitrile group, showing absorption at 2190 $\mathrm{cm}^{-1}$. However, exact assignment of these peaks is difficult as the peak position can be shifted by a change of environment and the double peak at 2100 and $2190 \mathrm{~cm}^{-1}$ may indicate the presence of only a single group, e.g., the isonitrile group, in two different environments. These chemical groups 
TABLE II. The FTIR absorption band positions for different possible bonding configurations in $\mathrm{CN}_{x}$ films (taken from Refs. 7 and 8).

\begin{tabular}{ccc}
\hline \hline $\begin{array}{c}\text { Absorption band } \\
{\left[\mathrm{cm}^{-1}\right]}\end{array}$ & Chemical group & $\begin{array}{c}\text { Bonding } \\
\text { configuration }\end{array}$ \\
\hline $\begin{array}{c}1330-1370 \\
\text { " } D \text { band" } \\
1530-1570\end{array}$ & disordered $s p^{2} / s p^{3}$ & $\equiv \mathrm{C}-\mathrm{N}<+=\mathrm{C}=\mathrm{N}=$ \\
" $G$ band" & graphitic $s p^{2} / s p^{3}$ & $=\mathrm{C}=\mathrm{N}=+\equiv \mathrm{C}-\mathrm{N}<$ \\
$1580-1680$ & $\mathrm{C}=\mathrm{N}, \mathrm{C}=\mathrm{C}$, or & $>\mathrm{C}=\mathrm{N}-,>\mathrm{C}=\mathrm{C}<$ \\
& $\mathrm{C}=\mathrm{C}+\mathrm{N}$ in chain & $>\mathrm{N}-\mathrm{C}=\mathrm{N}-,>\mathrm{C}=\mathrm{C}-\mathrm{N}$ \\
$2105-2155$ & carbodiimide & $-\mathrm{N}=\mathrm{C}=\mathrm{N}-$ \\
$2115-2175$ & isonitrile & $-\mathrm{N} \equiv \mathrm{C}$ \\
$2220-2230$ & nitrile & $-\mathrm{C} \equiv \mathrm{N}$ \\
\hline \hline
\end{tabular}

are clearly very similar and for convenience, this structure will be considered simply as $\mathrm{C} \equiv \mathrm{N}$. Some general bonding configurations found in the literature corresponding to the peaks present in these spectra are given in Table II. ${ }^{7,8}$

\section{XPS spectra}

The XPS N 1s results for samples $\mathrm{CN} 42$, CN54, and CN55 are presented in Fig. 3. The N 1s peak fitted spectra are given as it is this data which is more informative in following the changes in chemical structure. (It should be noted that there was a charge shift of approximately $0.8 \mathrm{eV}$ for the $140 \mathrm{~K}$ deposited sample, due to the low conductivity, which has been corrected in Fig. 3).

The N 1s peak for the $1500 \mathrm{~V}, 673 \mathrm{~K}$ deposited sample (CN42) is comprised of 3 components. The largest component occurs at $398.4 \mathrm{eV}$ and the second component is found at $400.25 \mathrm{eV}$. The third, very small peak occurs at $402.8 \mathrm{eV}$. The peak shape for the $150 \mathrm{~V}, 310 \mathrm{~K}$ sample (CN54) is almost identical. A reduction in the deposition temperature for this sputter voltage of $150 \mathrm{~V}$ results in a very weak $400.25 \mathrm{eV}$ peak. For all spectra, the splitting of these two peaks was always found to be between 1.8 and $1.9 \mathrm{eV}$. (In two of the spectra, the small peak occurring at around 395.0 $\mathrm{eV}$ is the Mo $3 p_{1 / 2}$ peak, present as a low concentration impurity from the molybdenum grids of the ion gun in the deposition chamber).

The assignment of the $\mathrm{N}$ 1s peaks are as follows. Sjöström et al. ${ }^{9}$ have reported calculations of two model systems in which a $\mathrm{N}$ atom is surrounded by $s p^{2}$ hybridized $\mathrm{C}$ (hexagonal $\mathrm{C}$ planes) or $s p^{3}$ hybridized $\mathrm{C}$ atoms. A $\mathrm{N} 1 \mathrm{~s}$ binding energy difference of $1.8 \mathrm{eV}$ between the two different structures was obtained. $\mathrm{N}-s p^{3} \mathrm{C}$ bonding corresponds to the peak at $398.4 \mathrm{eV}$ and $\mathrm{N}-s p^{2} \mathrm{C}$ to the peak at $400.25 \mathrm{eV}$. A depth profile of the $310 \mathrm{~K}$ sample, showed a slight increase of the small $402.8 \mathrm{eV}$ peak with depth, indicating that this peak corresponds to a bonding configuration within the material and is not due to oxidation or surface contamination. ${ }^{5}$ The origin of a peak at this high binding energy is not clear, but it is only found when the $\mathrm{N}-s p^{2} \mathrm{C}$ component is present and is probably a configuration involving planar $\mathrm{N}-\mathrm{N}$ bonding.

Returning to the IR spectrum, in addition to $\mathrm{N}-s p^{2} \mathrm{C}$ and $\mathrm{N}-s p^{3} \mathrm{C}$ bonding, the high energy peaks at 2100-2200
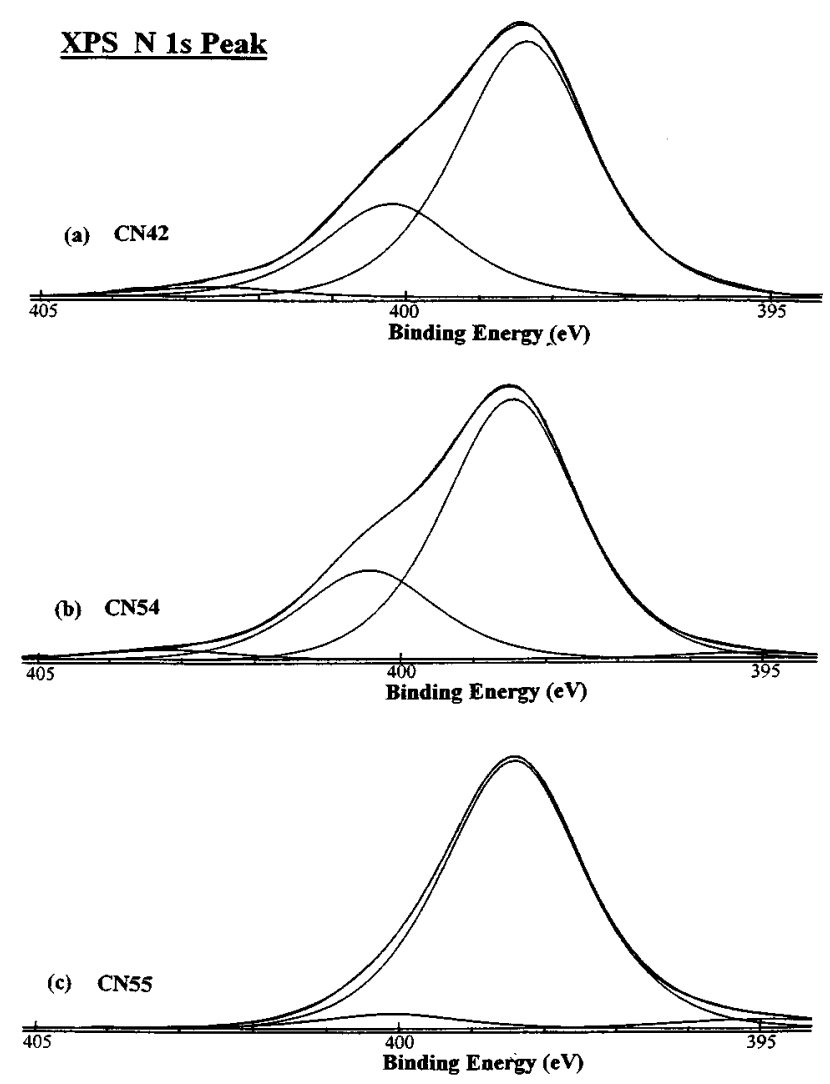

FIG. 3. XPS $\mathrm{N}$ ls spectra for three of the $\mathrm{CN}_{x}$ films given in Table I (a): CN42 (1500 V, $673 \mathrm{~K})(\mathrm{b})$ : CN54 (150 V, $310 \mathrm{~K})(\mathrm{c})$ : CN55 (150 V, 140 $\mathrm{K})$.

$\mathrm{cm}^{-1}$ correspond to $\mathrm{C} \equiv \mathrm{N}$ configurations and the $150 \mathrm{~V}$, low temperature depositions show a strong peak at 1600-1650 $\mathrm{cm}^{-1}$ due to doubly bonded groups $\mathrm{C}=\mathrm{N}$ and $\mathrm{C}=\mathrm{C}$.

As the $\mathrm{CN}$ structure changes from that based on a disordered $s p^{2} / s p^{3}$ hybridized carbon into a double and triple bonded structure, no new components emerge in the $\mathrm{N} 1 \mathrm{~s}$ peak. On the contrary, when the aromatic component becomes very weak, only one peak remains at $398.4 \mathrm{eV}$. This indicates that $\equiv \mathrm{C}-\mathrm{N}<\left(s p^{3} \mathrm{C}\right),>\mathrm{C}=\mathrm{N}-\left(s p^{2} \mathrm{C}\right)$, and $\mathrm{C} \equiv \mathrm{N}$ ( $s p \mathrm{C}$ ) type structures all exhibit the same binding energy at approximately $398.4 \mathrm{eV}$. Support for this comes from the literature, where the $\equiv \mathrm{C}-\mathrm{N}<$ and $>\mathrm{C}=\mathrm{N}-$ structures, have been reported to have binding energies of $398.4^{10,11}$ and $398.5 \mathrm{eV},{ }^{12}$ respectively. The $\mathrm{N} 1 \mathrm{~s}$ peak position for $-\mathrm{C} \equiv \mathrm{N}$ (nitrile) has been given as $399.4 \mathrm{eV},{ }^{13}$ but the binding energy for $-\mathrm{N} \equiv \mathrm{C}$ (isonitrile) would be expected at a lower value, due to the higher electron density at the $\mathrm{N}$ atom. The similarity of the $-\mathrm{N}=\mathrm{C}=\mathrm{N}-$ (carbodoiimide) and $>\mathrm{C}=\mathrm{N}-$ configurations also suggests that a binding energy of the same order is to be expected. Thus, it appears that in all aliphatic $\mathrm{CN}$ configurations, saturated or unsaturated, when $\mathrm{N}$ is bonded to more than one $\mathrm{C}$ atom, the distribution of the valence electron density around the $\mathrm{N}$ atom, and hence $\mathrm{N}$ 1s binding energy, is very similar.

The $\mathrm{C}$ 1s peaks for all of the samples are broad and rather featureless. With increasing $\mathrm{N}$ content, the peak broadens 
and shifts to higher binding energies due to the increasing number of $\mathrm{C}-\mathrm{N}$ bonds. The uncertainty of the many exact chemical environments makes a detailed interpretation and peak fitting untenable. However, for a $673 \mathrm{~K}$ sample with a $\mathrm{N}$ concentration of $\sim 20$ at. $\%$, the $\mathrm{C}$ peakshape can be well reproduced by a simulation incorporating peaks representing the possible $\mathrm{C}$ sites in an $s p^{2} / s p^{3}$ amorphous $\mathrm{C}$ type structure. $^{5}$

\section{Coupled interpretation of IR/XPS spectra}

It is now possible to make a detailed comparison of the IR and XPS results for the different samples. The high deposition voltage $673 \mathrm{~K}$ deposited sample (CN42), with the main IR absorption band having a maximum at around $1300 \mathrm{~cm}^{-1}$, indicates a mostly disordered $s p^{2} / s p^{3}$ structure. The presence of the two $\mathrm{N} 1 \mathrm{~s}$ peaks at $398.4\left(\mathrm{~N}-s p^{3} \mathrm{C}\right)$ and 400.25 $\mathrm{eV}\left(\mathrm{N}-s p^{2} \mathrm{C}\right)$ is in agreement with this. From the $\mathrm{N} 1 \mathrm{~s}$ spectrum of the $673 \mathrm{~K}$ sample, the large intensity of the $398.4 \mathrm{eV}$ component shows that $\mathrm{N}$ prefers a configuration in which it is bonded to $s p^{3}$ hybridized C. The atomic percentage of $\mathrm{N}$ bonded to $s p^{2} \mathrm{C}$ for this sample was calculated to be $6.0 \%$.

The film deposited at $150 \mathrm{~V}$ and $310 \mathrm{~K}$ (CN54), shows a shift in the main absorption band to higher wavenumberstowards the $G$ band at $1550 \mathrm{~cm}^{-1}$. Consequently, an increase in the $\mathrm{N}-s p^{2} \mathrm{C} / \mathrm{N}-s p^{3} \mathrm{C}$ ratio would be expected in the XPS spectrum. However, in Fig. 3, the $400.25 \mathrm{eV} / 398 \mathrm{eV}$ peak ratio for the $310 \mathrm{~K}$ sample is unchanged with respect to that for the $673 \mathrm{~K}$ sample. Evidence from other samples grown at beam voltages above $1000 \mathrm{~V}$, has suggested this to occur as a result of a rise in the fraction of $\mathrm{C} \equiv \mathrm{N}$ type bonds as the $\mathrm{N}$ content increases from 20 to 40 at. $\%$, the $\mathrm{C} \equiv \mathrm{N}$ overlapping with the $\mathrm{N}-s p^{3} \mathrm{C}$ component at $398.4 \mathrm{eV} .^{5}$ This behavior is in agreement with the IR spectrum for the 1000 $\mathrm{V}, 140 \mathrm{~K}$ grown CN58 sample, but is not so evident for the $150 \mathrm{~V}, 310 \mathrm{~K}$ sample. For this latter case, at a beam voltage of $150 \mathrm{~V}$ and substrate temperature of $310 \mathrm{~K}$, a small amount of $>\mathrm{C}=\mathrm{N}$ - bonding (which also overlaps the $398.4 \mathrm{eV}$ component) may also be present in the structure. The $140 \mathrm{~K}$ sample (CN55) shows an increase in the absorption at 1630 $\mathrm{cm}^{-1}$ and reduction in the intensity around $1500 \mathrm{~cm}^{-1}$. In addition, there is low intensity at low wavenumbers, indicating few singly bonded structures. In the $\mathrm{N}$ ls spectrum, the aromatic component has reduced to an almost negligible value. The film structure is approaching that of an aliphatic $\mathrm{CN}_{x}$ polymer.

\section{DISCUSSION}

Carbon nitride films deposited using a high sputter voltage at 673 and $140 \mathrm{~K}$ show small variation in their optical, electrical, and structural properties. At this high sputter beam and voltage, predominantly neutral carbon atoms are sputtered from the target and the chemical bonding between carbon and nitrogen to form the $\mathrm{CN}_{x}$ layer is occurring on the growing film surface. The spectral results together with the relatively high conductivity and the low band gap suggest an electronic structure having a large number of delocalized $\pi$-type band tail states indicating a structure based on that of $s p^{2} / s p^{3}$ amorphous carbon. $\mathrm{N}$ is incorporated into both $s p^{2}$ and $s p^{3}$ hybridized structures, the latter being the preferential site.

Reducing the sputter beam voltage to $150 \mathrm{~V}$ results in a change in the sputter gas composition. In addition to neutral carbon, $\mathrm{HCN}$ and $\mathrm{C}_{2} \mathrm{~N}_{2}$ molecules are also present. At 310 $\mathrm{K}$, this has little effect on the film structure and properties as these molecules are volatile at this temperature. The conductivity is slightly reduced. Although not clearly evident from the IR spectra, this is possibly due to some doubly bonded groups replacing the aromatic structures. The number of $\mathrm{N}-s p^{2} \mathrm{C}$ bonds has also increased, reducing the abundance of the highly delocalized graphitic rings.

As the substrate temperature is reduced to 140 and $80 \mathrm{~K}$, the chemically sputtered molecules condense at the substrate surface causing a large change in the film properties. The band gap opens to $2.2 \mathrm{eV}$ with a concomitant decrease in the conductivity. The XPS spectra show a large reduction in the amount of $\mathrm{N}$ incorporated into aromatic structures and the IR spectra indicate that these aromatic structures are being replaced by double bonds. As a consequence, the reduced density of delocalized $\pi$ states increases the band gap and reduces the number of conduction electrons. There are, to a lesser extent, triple bonded and singly bonded structures. Although there is not enough data to make assertive statements, the hardness seems to decrease as (i) the beam voltage is reduced to from 1000 to $150 \mathrm{~V}$, (ii) the substrate temperature is decreased, and (iii) the $\mathrm{N}$ content is increased above $20 \%{ }^{2}$

With respect to a growth mechanism, it can be envisaged that a deposition at low temperatures and low sputter voltages giving a structure containing a large percentage of double and triple bonds results from a limited amount of bond breaking of the triply bonded gaseous precursors of the film. When condensed at the substrate, these compounds have their surface diffusion limited by the low temperatures and hence bind together, forming a linear polymeric type structure.

As a $\mathrm{CN}_{x}$ compound which contains $44 \%$ nitrogen and is obtained by polymerization of $\mathrm{C} \equiv \mathrm{N}$ containing compounds such as cyanogen and hydrogen cyanide, this film is most comparable to paracyanogen. The IR spectra given by Bircumshaw et al. ${ }^{14}$ of paracyanogen prepared by different methods show some similarities and some differences to those obtained here. A broad band, centered at $1570 \mathrm{~cm}^{-1}$ was observed for all samples and a peak at $2070 \mathrm{~cm}^{-1}$ was obtained after dissolving these paracyanogens in $\mathrm{H}_{2} \mathrm{SO}_{4}$ and precipitating in $\mathrm{H}_{2} \mathrm{O}$. The authors interpreted the results to be indicative of a complete conjugated double bond system and suggested various planar structures for the compound. It has been seen that for this film, the results support a polymeric chain and not a cyclic planar structure and that the polymer is composed of triple and single bonds in addition to the predominant double bonds.

A reduction of the sputter voltage to $150 \mathrm{~V}$ and substrate temperature to $140 \mathrm{~K}$ has enabled the nitrogen contents of $\mathrm{CN}_{x}$ films grown by dual ion beam sputtering to attain 44 
at. \%. A further increase of the nitrogen concentration by using high $\mathrm{N}_{2}^{+}$assisting current densities is prevented by chemical etching. The polymeric structure which results from such deposition parameters, gives rise to a transparent poorly conducting film exhibiting a low density and low hardness.

\section{CONCLUSIONS}

$\mathrm{CN}_{x}$ films have been deposited by dual ion beam sputtering at different sputter beam voltages and substrate temperatures. At high sputter beam voltages, physical sputtering is the dominant mechanism with predominantly neutral $\mathrm{C}$ atoms being sputtered from the target. Films grown at substrate temperature of 673 and $140 \mathrm{~K}$ exhibit a similar structure and properties. These films are opaque, highly conductive, contain up to $34 \%$ nitrogen, exhibit a hardness of $20 \mathrm{GPa}$, and a density similar to that of graphite. Their structure is that of $s p^{2}$ hybridized aromatic rings, cross linked by $s p^{3}$ hybridized carbon, with $\mathrm{C} \equiv \mathrm{N}$ groups being incorporated above a $\mathrm{N}$ concentration of $20 \%$. Reducing the sputter voltage to $150 \mathrm{~V}$ promotes chemical etching and the sputtering of $\mathrm{C} \equiv \mathrm{N}$ based molecules. At $310 \mathrm{~K}$, the difference in the composition of the molecular precursors of the film have little effect on the structure and properties, the layer being similar to those produced at high sputter beam voltages. Reducing the substrate temperature to 140 and $80 \mathrm{~K}$, results in only limited bond breaking of the condensing triple bonded $\mathrm{CN}$ species and a new $\mathrm{CN}_{x}$ phase with high nitrogen content of up to $44 \%$ is formed. This material exhibits a large optical band gap and very low conductivity. The spectroscopic in- formation confirm that these properties occur as a result of a decrease in the delocalized aromatic component, these structures being replaced by localized double bonds. The film also contains singly and triply bonded groups. All of these groups are bound together to form a chainlike polymeric structure.

\section{ACKNOWLEDGMENTS}

The authors would like to acknowledge Dr. J. Haupt for providing the hardness results and A. Hofmann for his technical assistance in the deposition laboratory.

${ }^{1}$ P. Hammer and W. Gissler, Diam. Relat. Mater. 5, 1152 (1996).

${ }^{2}$ P. Hammer, M. A. Baker, C. Lenardi, and W. Gissler, Thin Solid Films (to be published).

${ }^{3}$ S. S. Todorov, D. Marton, K. J. Boyd, A. H. Al-Bayati, and J. W. Rabalais, J. Vac. Sci. Technol. A 12, 3192 (1994).

${ }^{4}$ A. Y. Liu and M. L. Cohen, Phys. Rev. B 41, 10727 (1990).

${ }^{5}$ M. A. Baker and P. Hammer, Surf. Interface Anal. (submitted).

${ }^{6}$ J. H. Kaufman, S. Metin, and D. D. Saperstein, Phys. Rev. B 39, 13053 (1989).

${ }^{7}$ D. Dolphin and A. Wick, Tabulation of Infrared Spectral Data (Wiley, New York, 1977).

${ }^{8}$ G. Socrates, Infrared Characteristic Group Frequencies (Wiley, Chichester, U.K., 1980).

${ }^{9}$ H. Sjöström, S. Stafström, M. Boman, and J. E. Sundgren, Phys. Rev. Lett. 75, 1336 (1995).

${ }^{10}$ D. Marton, A. H. Al-Bayati, S. S. Todorov, K. J. Boyd, and J. W. Rabalais, Nucl. Instrum. Methods Phys. Res. B 90, 277 (1994).

${ }^{11}$ H. Sjöström, L. Hultman, J.-E. Sundgren, S. V. Hainsworth, T. F. Page, and G. S. A. M. Theunissen J. Vac. Sci. Technol. A 14, 56 (1996).

${ }^{12}$ D. Briggs, D. T. Clark, H. R. Keable, and M. Kilner J. Chem. Soc. Dalton Trans., 2143 (1973).

${ }^{13}$ M. Barber, J. A. Conner, M. F. Guest, I. H. Hillier, M. Schwartz, and M. Stacey, J. Chem. Soc. Faraday Trans. II 69, 551 (1973).

${ }^{14}$ L. L. Bircumshaw, F. M. Tayler, and D. H. Whiffen, J. Chem. Soc. 931 (1954). 